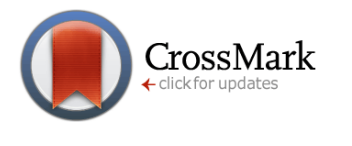

*For correspondence:

alesaleh70@yahoo.com

Competing interests: The authors declare that no competing interests exist.

Received: 19 September 2016

Accepted: 20 October 2016

Published: 29 October 2016

Copyright The Author(s) 2016. This article is published with open access by BioMedPress (BMP).

This article is distributed under the terms of the Creative Commons Attribution License (CC-BY 4.0) which permits any use, distribution, and reproduction in any medium, provided the original author(s) and the source are credited.

\title{
Epidemiology, incidence and mortality of oral cavity and lips cancer and their relationship with the human development index in the world
}

\section{Fariba Ramezani Siakholak1, Mahshid Ghoncheh², Reza Pakzad ${ }^{3}$, Hamidreza Sadeghi Gandomani4, Fereshteh Ghorat ${ }^{5}$, Hamid Salehiniya ${ }^{6,7 *}$}

\footnotetext{
${ }^{1}$ Health Promotion Research Center, Department of Epidemiology and Biostatistics, School of Public Health , Zahedan University of Medical Sciences, Zahedan, Iran

${ }^{2}$ Department of Epidemiology and Biostatistics, School of public health, Hamadan University of Medical Sciences, Hamadan, Iran

${ }^{3}$ Student Research committee, Ilam University of Medical Sciences, Ilam, Iran

${ }^{4}$ Trauma Nursing Research Center, Faculty of Nursing and Midwifery, Kashan University of Medical Sciences, Kashan, Iran

${ }^{5}$ Research center of Traditional medicine, Sabzevar university of medical sciences, Iranian Traditional medicine association, Sabzevar, Iran

${ }^{6}$ Zabol University of Medical Sciences, Zabol, Iran

7 Department of Epidemiology and Biostatistics, school of public health, Tehran University of Medical Sciences, Tehran, Iran
}

\begin{abstract}
Introduction: According to the importance of knowledge about incidence and mortality of oral cavity and lip cancer in health planning, this study was performed with the aim of investigating the incidence and mortality rate of oral cavity and lip cancer and its relation with the Human Development Index in the world in 2012. Methods: The study was conducted based on data from the world data of cancer and the World Bank (including the HDI and its components). Data about the age-specific incidence and mortality rate (ASR) for every country in 2012 were getting from the global cancer project.
\end{abstract}


To analyze data, correlation tests between incidence and death rates, and HDI and its components were employed with a significance level of 0.05 using SPSS software. Results: In 2012, 300373 cases of oral cavity and lip cancer and 145353 cases of death from it have occurred in the world. A positive correlation of 0.221 was seen between the standardized incidence rate of oral cavity and lip cancer and HDI but this correlation was not statistically significant $(p=0.114)$. On the other side, a correlation of 0.295 was seen between the standardized mortality rate of oral cavity and lip cancer with HDI that this correlation was statistically significant $(p<0.001)$. Conclusion: The incidence and mortality of oral cavity cancer is high in the Asian countries especially south eastern of Asia. Performing preventive plans in high incidence and mortality rate regions and also obtaining etiological studies in these regions is recommended for diagnosing the causes of high incidence and mortality rates.

\section{Keywords}

Incidence, mortality, development, world, oral cavity, lips cancer

\section{Introduction}

Today, after heart disease, the cancer is the most common cause of death in many countries Unfortunately, the number of cancer patients is increasing (Ghoncheh et al., 2016; Rafiemanesh et al., 2016; Sciubba jj, 1999) as more than 10 million new cases and more than 6 million deaths occur each year worldwide (Petersen, 2009).

Among cancers, oral cancer is one of the most common cancers. According to the International Agency for Research on Cancer, the amount of the sufferers from the disease is increasing in coming years (Pereira et al., 2007). In most cases, predominant form of this cancer type is squamous cell carcinoma (Mukherjee et al.) that because of side effects and high mortality rates, is considered as one of the important threats in public health (Stîngă et al., 2011). Squamous cell carcinoma is a malignant neoplasm that arises from squamous epithelium which can be found on both oral cavity (oral mucosa, gums, hard palate, tongue, and mouth) and on lip (Batista et al., 2010).

In most countries, oral cavity cancer in men is more than women. Its risk increases by aging and mortality occurs in 50 years and older. The incidence of oral cancer (except lip) is more in South and Southeast Asia (Sri Lanka, India, Pakistan and Taiwan), parts of the West (France) and East Europe (Hungary, Slovakia and Slovenia), parts of Latin America and the Caribbean (Brazil, Uruguay and Puerto Rico) and in the Pacific (Papua New Guinea and Melanesia). The highest incidence of lip cancer has been reported between white populations in Canada and Australia that is rare among non-whites (Warnakulasuriya, 2009a). 
The main cause of the incidence of this cancer is the high consumption of tobacco, especially among consumers of smokeless tobacco, excessive alcohol consumption, and exposure to the sun's ultraviolet rays (Ariyawardana and Johnson, 2013; Listl et al., 2013). Also infection of human papillomavirus (Dodd et al., 2016) has been reported a as risk factor for this cancer.

WHO (World Health Organization) has considered necessary actions for controlling the oral cavity cancer as a health priority (Priya and Lando, 2014). So that can be detected through routine examination, but the 5 year survival rate is low (Ahluwalia et al., 1998). Oral cancer is preventable by controlling tobacco, alcohol and sun exposure (Elter et al., 2005).

To avoid overload of non-communicable diseases especially in low and middleincome countries that already include $80 \%$ of burden of disease worldwide, a global action is needed. Cancer is the main cause of morbidity and mortality in many regions of the world.So the HDI (Human Development Index) and considered as a marker of socioeconomic development and incidence and mortality of cancer (Bray et al., 2012; Mahdavifar et al., 2016; Pakzad et al., 2015; Razi et al., 2016). HDI is a composite index which has three dimensions: education, life expectancy and national income. That according to the United Nations Development, the countries are categorized on 4 levels: low, medium, high and very high (Soltani et al., 2015). Since the knowledge about the incidence and mortality of oral cavity cancer can be useful for health programs and research activities and with regard to the possible role of the Human Development Index, this study has taken place with the aim of investigating the incidence and mortality of lip and oral cavity cancer and its relationship with development index and its components in the world in 2012.

\section{Methods}

This study was an ecologic study in the World for assessing the correlation between age-specific incidence and mortality rate (ASR) with HDI and its details, including life expectancy at birth, mean years of schooling, and Gross national income (GNI) per capita. Data about the age-specific incidence and mortality rate (ASR) for every country in 2012 were get from the global cancer project that available in http://globocan.iarc.fr/Default.aspx (Ferlay J et al., 2016) and HDI from Human Development Report 2013 (Malik, 2013), that includes information about HDI and its details for every country in the word in 2012.

Method for estimating the age-specific incidence and mortality rates in global cancer project by international agency for research on cancer:

\section{Age-specific incidence rate estimate}


The methods of estimation are country specific, and the quality of the estimation depends upon the quality and on the amount of the information available for each country. In theory, there are as many methods as countries, and because of the variety and the complexity of these methods, an overall quality score for the incidence and mortality estimates combined is almost impossible to establish. However, an alphanumeric scoring system which independently describes the availability of incidence and mortality data has been established at the country level. The combined score is presented together with the estimates for each country with an aim of providing a broad indication of the robustness of the estimation.

The methods to estimate the sex- and age-specific incidence rates of cancer for a specific country fall into one of the following broad categories, in priority order:

1- Rates projected to 2012 (38 countries)

2- Most recent rates applied to 2012 population (20 countries)

3- Estimated from national mortality by modelling, using incidence mortality ratios derived from recorded data in country-specific cancer registries (13 countries)

4- Estimated from national mortality estimates by modelling, using incidence mortality ratios derived from recorded data in local cancer registries in neighboring countries (9 European countries)

5- Estimated from national mortality estimates using modelled survival (32 countries)

6- Estimated as the weighted average of the local rates (16 countries)

7- One cancer registry covering a part of a country is used as representative of the country profile (11 countries)

8- Age/sex specific rates for "all cancers" were partitioned using data on relative frequency of different cancers (by age and sex) (12 countries)

9- The rates are those of neighboring countries or registries in the same area (33 countries) (Ferlay J et al., 2016).

\section{Age-specific mortality rate estimate}

Depending on the degree of detail and accuracy of the national mortality data, six methods have been utilized in the following order of priority:

1- Rates projected to 2012 (69 countries)

2- Most recent rates applied to 2012 population (26 countries) 
3- Estimated as the weighted average of regional rates (1 country)

4- Estimated from national incidence estimates by modelling, using countryspecific survival (2 countries)

5- Estimated from national incidence estimates using modelled survival (83 countries)

6- The rates are those of neighboring countries or registries in the same area (3 countries) (Ferlay et al., 2015).

\section{Human Development Index (HDI)}

$\mathrm{HDI}$ is a composite measure of indicators along three components, including life expectancy, educational attainment, and command over the resources needed for a decent living. All groups and regions have seen notable improvement in all HDI components, with faster progress in low and medium HDI countries. On this basis, the world is becoming less unequal. Nevertheless, national averages hide large variations in human experience. Wide disparities remain within countries of both the North and the South, and income inequality within and between many countries has been rising. According to HDI, countries in the world are divided into four categories as follows: countries with very high $\mathrm{HDI}(\mathrm{HDI} \geq=0.80)$, countries with a high $\mathrm{HDI}(0.80>\mathrm{HDI}>0.710)$, medium $\mathrm{HDI}$ countries $(0.710 \geq$ $H D \geq 0.535)$, and countries with a low HDI (HDI < 0.535) (Malik, 2013).

\section{Statistical analysis}

In this study, we used correlation bivariate method for assessment of the correlation between age-specific incidence and mortality rate (ASR) with HDI and its details, which include life expectancy at birth, mean years of schooling, and $\mathrm{GNI}$ per capita. Statistical significance was assumed if $\mathrm{P}<0.05$. All reported $\mathrm{P}$ values are two-sided. Statistical analyses were performed using SPSS (Version 15.0, SPSS Inc.).

\section{Results}

\section{The incidence number of lip and oral cavity cancer}

In 2012, 300373 cases of lip and oral cavity cancer had occurred in the world that 198975 cases of them were men and 101398 cases were women (Sex ratio=1.96). Among all cases, 92338 cases were in countries with very high HDI, 45734 cases in countries with a high HDI, 121240 cases in average HDI countries and 40954 cases in countries with a low HDI. Five countries that the highest number of Lip and oral cavity cancers have had occurred in them included India with 77003 cases, America with 26064 cases, 21413 cases in China, Bangladesh with 10550, and Pakistan with 12761 cases. Five countries with the highest 
number of lip and oral cavity cancer in men were India with 53842 cases, America with about 17325 cases, China with about 13656 cases, Russia with 7451 cases, and Bangladesh with 7120 cases, respectively. 5 countries which have the most cases of lip and oral cavity cancer include India with 23161 cases, America with 8739 cases, china with 7757 cases, Pakistan with 5693 cases, and Brazil with 3509 cases.

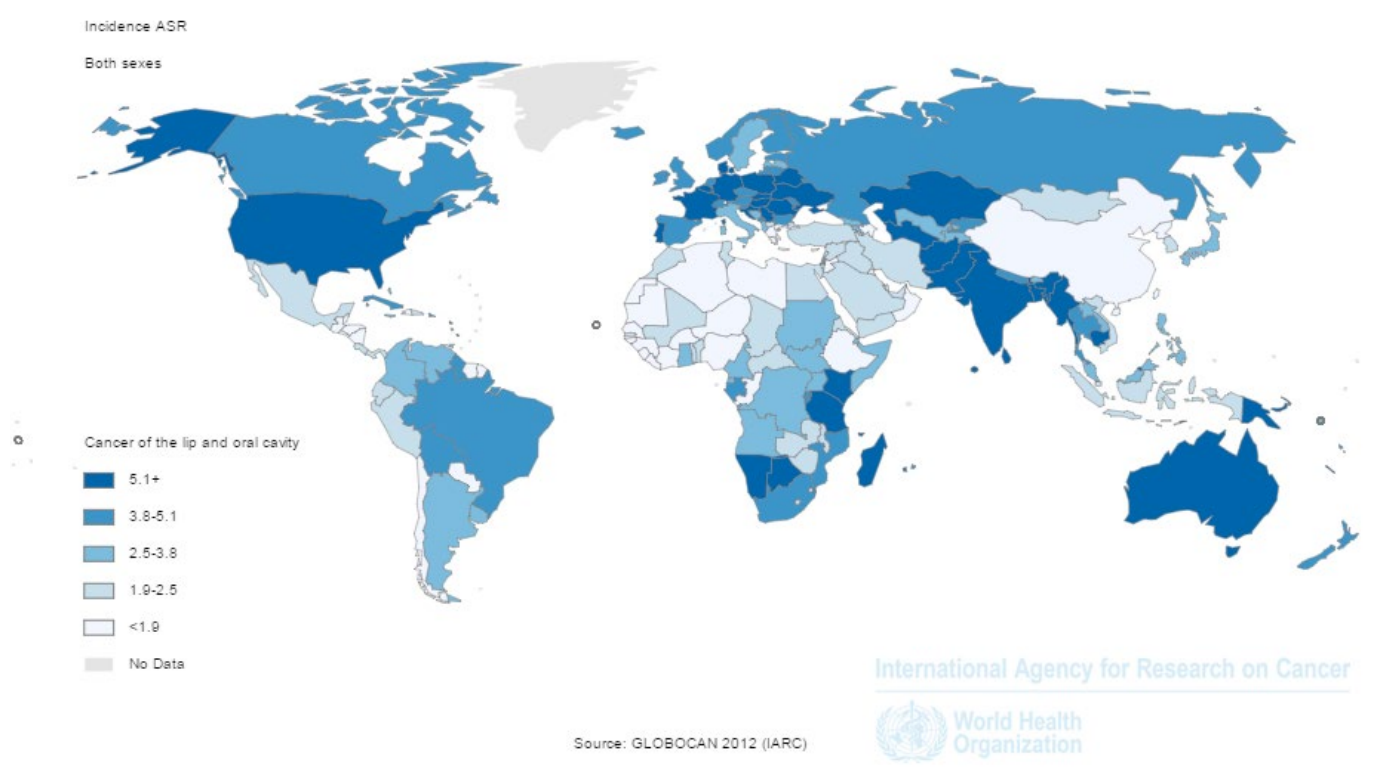

Figure 1. Distribution of the standardized incidence rate of oral cavity and lips cancer in the world (extracted from GLOBOCAN 2012).

\section{Age-standardized incidence rate of Lip and oral cavity cancer}

The standardized incidence rate of lip and oral cavity cancer was4 in every hundred thousand in the world that it was 5.5 in men and 2.5 in women per hundred thousand. Standardized incidence rate of lip and oral cavity cancer in countries with very high HDI was 2.7 per 100 thousand people, in countries with high HDI was 2.1 per hundred thousand people, in countries with average HDI was 2.2 per hundred thousand, and in countries with low HDI, it was 4 per hundred thousand people. Five countries with the highest age-standardized incidence rate of lip and oral cavity cancer were Papua New Guinea with 25 cases per hundred thousand people, Maldives with 11 cases per hundred thousand people, Sri Lanka with 10.3 cases per hundred thousand people, Pakistan with 9.8 cases per hundred thousand people, and Hungary with 9.7 cases per hundred thousand people, respectively. 5 countries with the highest age-standardized incidence rate of lip and oral cavity cancer for men include: Papua New Guinea with 30.3 cases per hundred thousand people, Hungary with 15.7 cases per hundred thousand people, Sri Lanka with 15.4 cases per hundred thousand people, Maldives with 15.4 cases per hundred thousand people, and France, La Reunion with 13.7 cases per hundred thousand people. Also 5 
countries with the highest age-standardized incidence rate of lip and oral cavity cancer for women include Papua New Guinea, with 21.1 cases per hundred thousand people, Pakistan with 9.1 cases per hundred thousand people, Brunei with 9 cases per hundred thousand people, Maldives with 6.4 cases per hundred thousand people, and Bangladesh with 5.9 cases per hundred thousand people (Fig. 1).

\section{The mortality number of lip and oral cavity cancer}

In 2012, 145353 deaths occurred from lip and oral cavity worldwide from which about 97940 cases related to men and 47413 cases related to women (Sex Ratio = 2.06). The number of deaths from cancer in very high $\mathrm{HDI}$ countries was about 26970 cases; about 19615 cases in high HDI countries, 73503 cases in average HDI countries and 25235 cases in low HDI countries. The five countries with the highest number of deaths from lip and oral cavity cancer included India with 52067 deaths, China with 11,333 deaths, 7266 deaths in Pakistan, Bangladesh with 6071 deaths, and Russia with 5658 deaths. Five countries with the most cases of death from lip and oral cavity cancer in men included India with 36,436 deaths, China, with 7370 deaths, Russia with 4472 deaths, Bangladesh with 4094 deaths, and Pakistan with 4046 deaths. Also, five countries with the most cases of death from lip and oral cavity cancer in men included India with15631 deaths, China with 3963 deaths, Pakistan with 3220 deaths, Bangladesh with 1977 deaths, and 1806 cases of death in Japan.

\section{Age-standardized mortality rate of lip and oral cavity cancer}

In 2012, the standardized mortality rate of lip and oral cavity cancer was 1.9 per hundred thousand people in the world that this rate was2.7 in men and 1.2 in women per hundred thousand people. The standardized mortality rate of lip and oral cavity cancer in countries with very high HDI was 1.2 per hundred thousand people, in countries with high HDI 1.6 per hundred thousand people, in countries with average HDI 2 per hundred thousand, and in countries with low HDI was 3.3 per hundred thousand people. 5 countries which had the highest standardized death rate of lip and oral cavity cancer were Papua New Guinea with 16 per hundred thousand people, Pakistan with 5.9 per hundred thousand, Bangladesh with 5.6 per hundred thousand, Afghanistan with 5.1 per hundred thousand people, and India with 4.9 per hundred thousand people, respectively. 5 countries which had the highest standardized mortality rate of lip and oral cavity cancer for men were Papua New Guinea with 19.4 per hundred thousand, Hungary with 7.9 per hundred thousand, Bangladesh with 7.7 per hundred thousand, Belarus with 7.1 per hundred thousand people, and India with 6.7 per hundred thousand people, respectively. Also, 5 countries which had the highest standardized mortality rate of lip and oral cavity cancer for women were Papua New Guinea with 13.6 per hundred thousand people, Pakistan with 5.4 per hundred thousand, Afghanistan with 4.3 per hundred thousand, Comoros with 4.3 per hundred thousand people, and Bangladesh with 3.5 per hundred thousand people, respectively (Fig. 2). 
Figure 3 shows standardized incidence and mortality rate of lip and cavity cancer in different parts of UN. As it is clear, the standardized incidence rate of lip and oral cavity cancer in undeveloped countries and South Asia is more than developed countries. But mortality of lip and oral cavity cancer is higher in less developed countries than in developed and developing ones (Fig. 3).

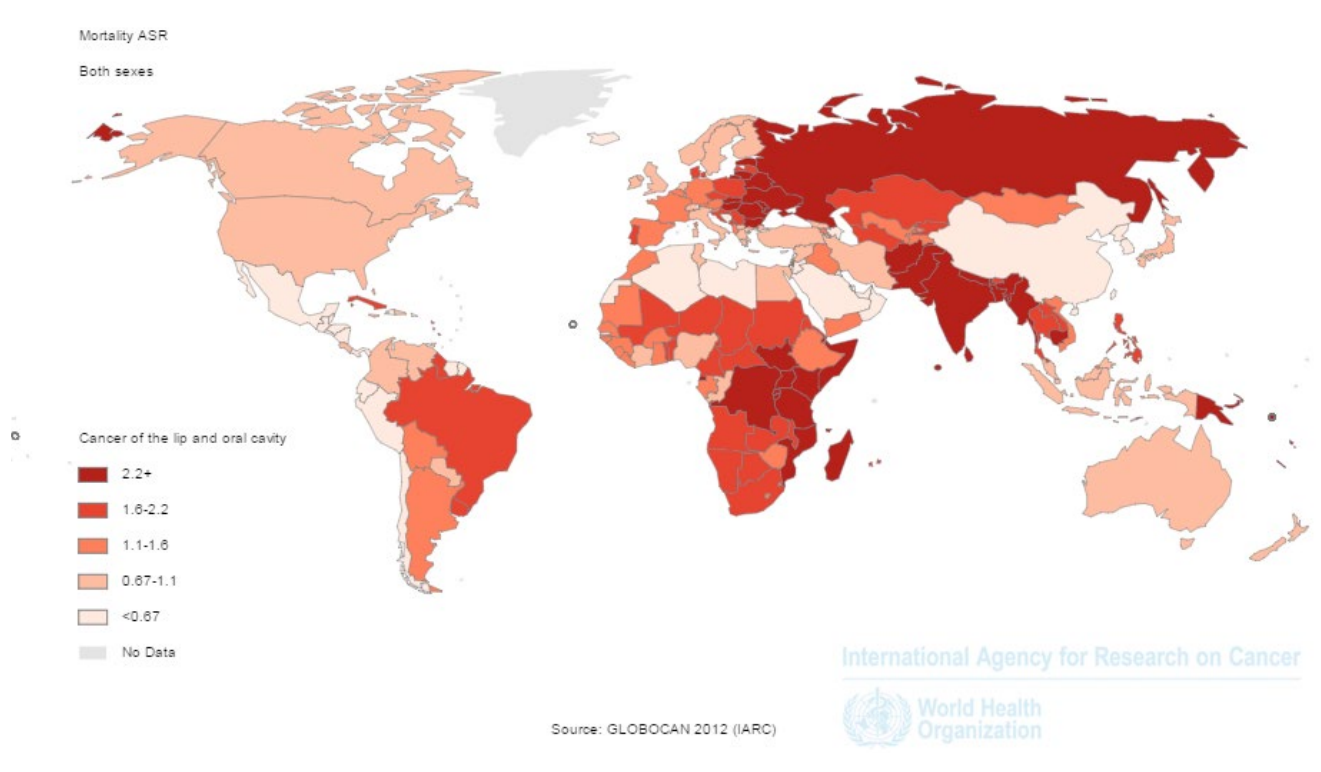

Figure 2. Distribution of the standardized mortality rate of oral cavity and lips cancer in the world (extracted from GLOBOCAN 2012).

\section{The relationship between the standardized incidence rate of lip and oral cavity cancer and the human development index}

A positive correlation of 0.122 was seen between the standardized incidence rate of lip and oral cavity cancer and HDI but it was not statistically significant $(p=0.114)$.

Also, a positive correlation was seen between components of the human development index and standardized incidence rate of lip and oral cavity cancer. So that positive correlation between standardized incidence rate with life expectancy at birth was 0.116 ( $p=0.134)$, with mean age of education equaled to $0.123(p=0.111)$, and with the level of income per person of the population was $0.072(p=0.352)$ that none were statistically significant (Fig. 4 and Table 1). 
Lip, oral cavity: both sexes, all ages

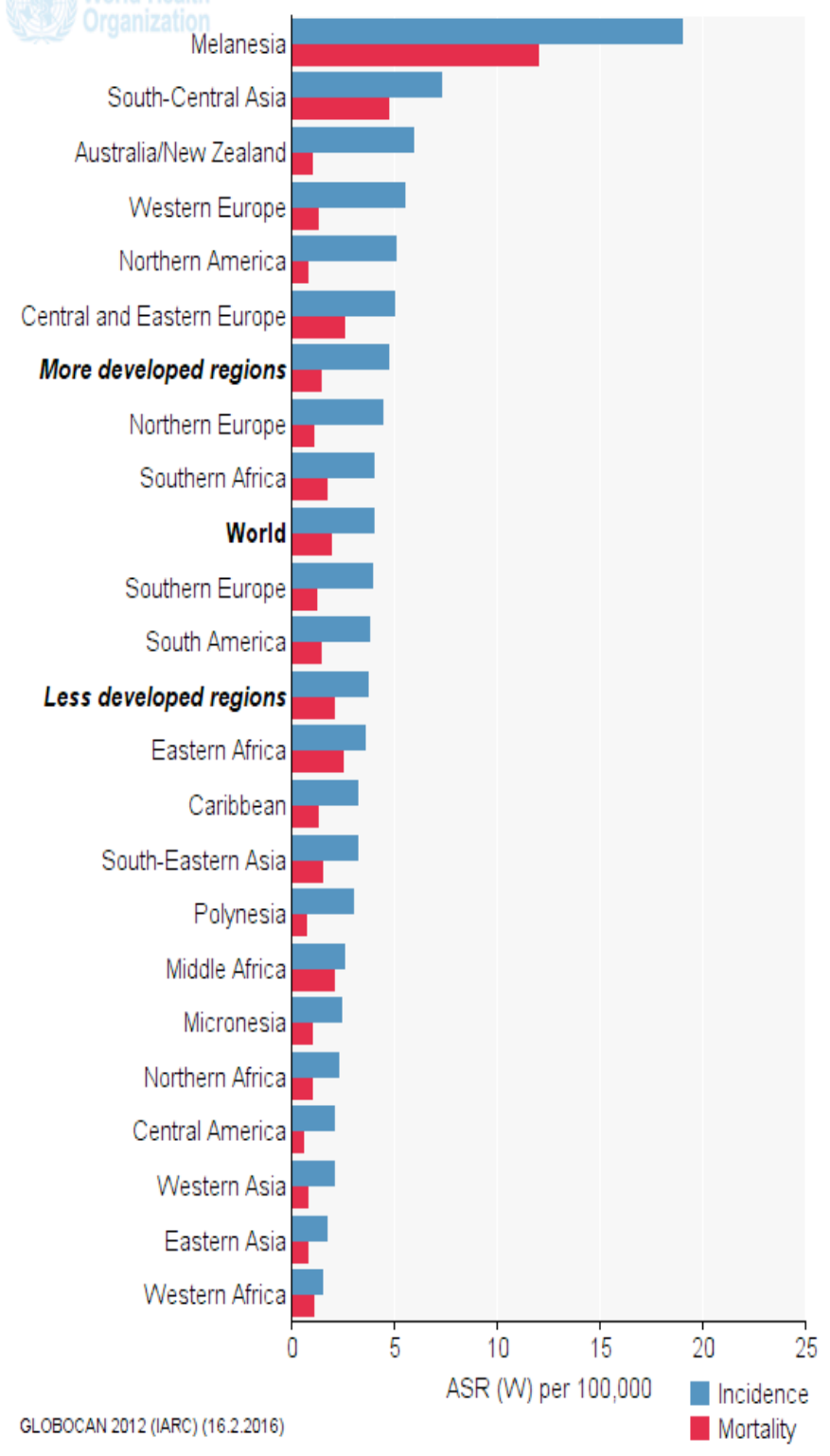

Figure 3.

Standardized incidence and mortality rate in different regions of UN (extracted from GLOBOCAN 2012).

The relationship between the age-standardized mortality rate of Lip and oral cavity cancer and the Human Development Index

A negative correlation of -0.295 was seen between the standardized mortality rate of lip and oral cavity cancer and the Human Development Index, that this association was statistically significant $(p<0.001)$. Also, a negative correlation was seen between components of the Human Development Index and standardized mortality rate of Lip and oral cavity cancer. So that a negative correlation of $-0.264(p=0.001)$ was seen between standardized mortality rate and life expectancy at birth, a correlation of -0.26 with the average years of education $(p=0.001)$, and a 
negative correlation of -0.248 with income level per each person of population ( $p=0.001$ ) (Fig. 5 and Table 1).

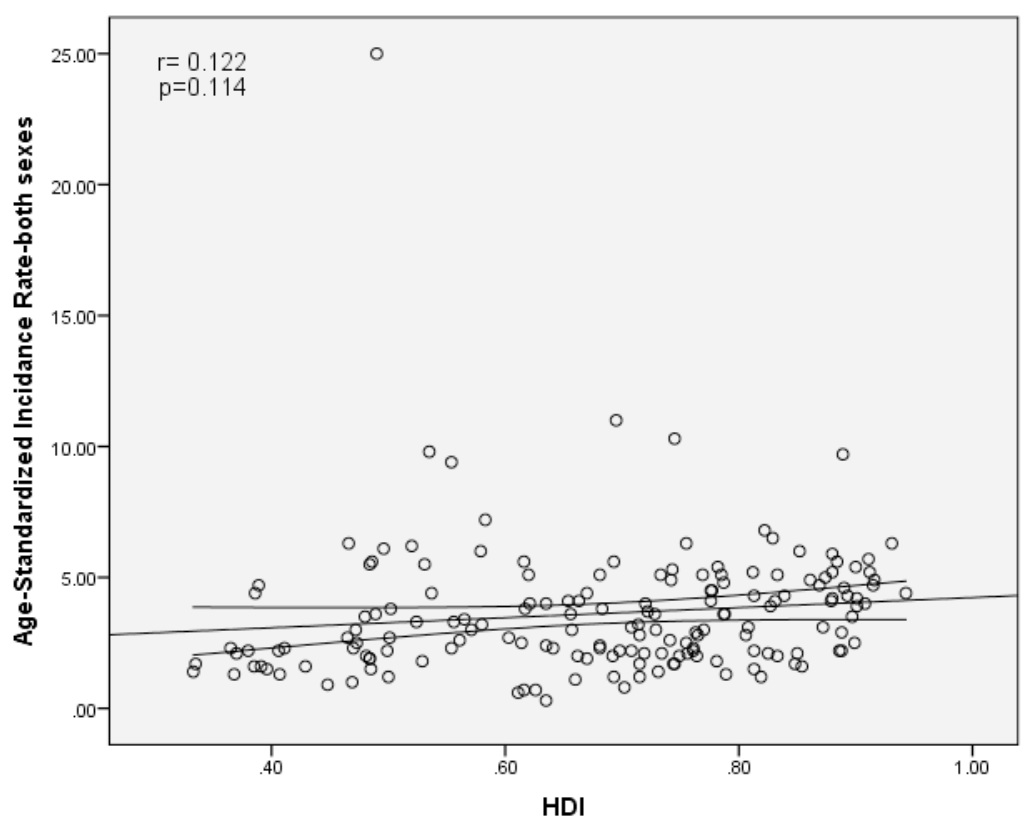

Figure 4. The relation between the standardized incidence rate and the human development index.

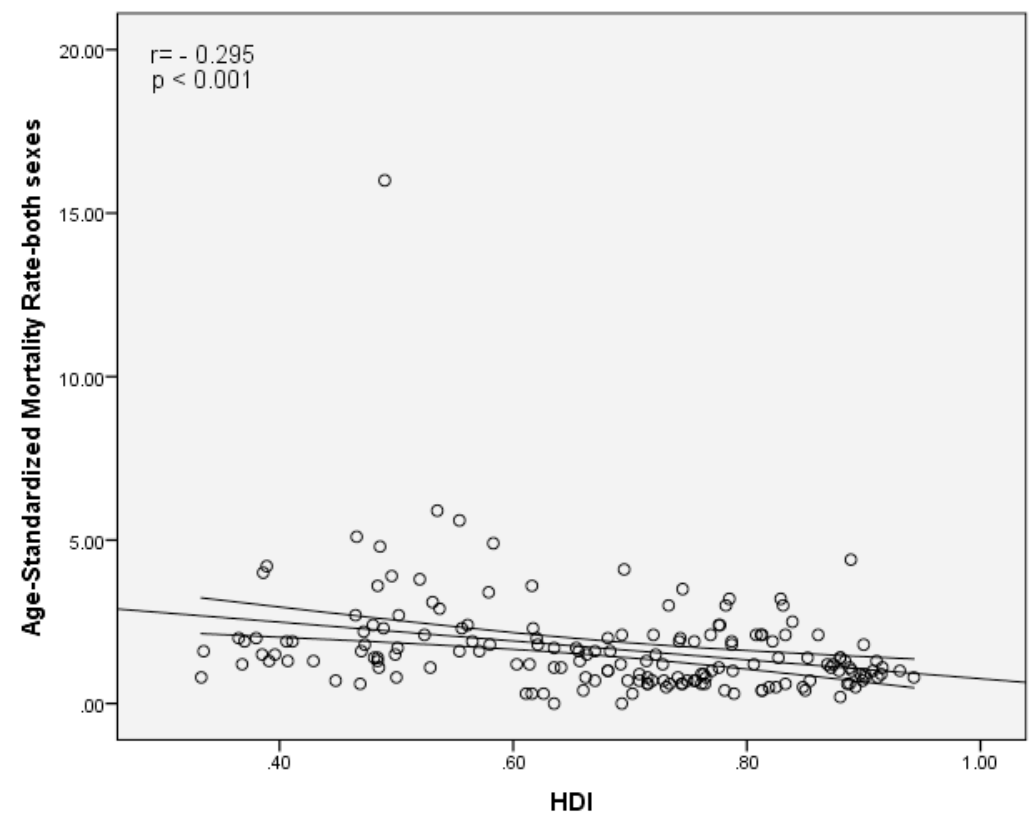

Figure 5. The relation between the standardized mortality rate and the human development index. 
Table 1. Correlation between ASIR, ASMR with HDI and its components

\begin{tabular}{|c|c|c|c|c|}
\hline Variables & HDI & LEY & Literacy & GNP \\
\hline \multirow{2}{*}{ ASIR } & $r=0.122$ & $r=0.116$ & $r=0.123$ & $r=0.072$ \\
& $p=0.114$ & $p=0.134$ & $p=0.111$ & $p=0.483$ \\
\hline \multirow{2}{*}{ ASMR } & $r=-0.295$ & $r=-0.264$ & $r=-0.26$ & $r=-0.248$ \\
& $p<0.001$ & $p=0.001$ & $p=0.001$ & $p=0.001$ \\
\hline
\end{tabular}

ASIR: Age-standardized Incidence Rate, ASMR: Age-Standardized Rate

\section{Discussion}

Cancer is a major cause of death worldwide which was the cause of 6.7 million deaths in 2008 (Soerjomataram et al., 2012). Oral squamous cell carcinoma is one of the most common tumors in head and neck that can affect both mouth and lip squamous area (Oliveira-Neto et al., 2012). About 264,000 new cases and 128,000 deaths from it have happened in 2008 that about 172,000 cases and 97,000 deaths were in developed countries (Sankaranarayanan et al., 2013).

The concern about lip and oral cavity area is related to high incidence of malignant tumors in this areas compared to other areas of head and neck. complications and mortality which occur from squamous cell carcinoma diagnosis which is a the diagnosed tissue, that can be found $40 \%$ in lip and oral cavity, $25 \%$ in the larynx and $15 \%$ in the throat with a low incidence in oral area (Ribeiro et al., 2015). In addition, oral cancer disease burden is high due to the high cost of treatment, permanent impairment and mortality (Rao et al., 2013).

The results of this study showed that the highest standardized incidence rate of lip and oral cavity cancer is related to Papua New Guinea, Maldives, Sri Lanka, Pakistan and Hungary. The first four countries are located in medium level and Hungary is located in high in terms of Human Development Index . On the other hand, Papua New Guinea, Pakistan, Bangladesh, Afghanistan and India have the highest standardized death rates that those mentioned countries were in average and low levels in the terms of the HDI (Soltani et al., 2015). 
The Mortality and incidence rates of oral cancer varies widely throughout the world as the highest amount has been recorded in developing countries including India, Pakistan, Bangladesh, Hong Kong, Singapore and the Philippines that oral cancer is the most common form of cancer in it (La Vecchia et al., 1997). Standardized incidence rate of oral cancer in West Europe are rising unevenly in two decades (Warnakulasuriya, 2009a). The incidence of oral cancer is high in Asian countries, especially South East Asia (Rao et al., 2013). Asians have the highest risk of oral cancer compared to other populations and other races/ethnicities which is more associated with their lifestyles (Warnakulasuriya, 2010). In South Asia, India is mentioned as the country with the highest incidence of oral cancer (Warnakulasuriya, 2009a).

Smoking, alcohol consumption, sun exposure and viral infections, previous events of head and neck cancer and socioeconomic status can be related to the occurrence of lip and oral cavity cancer (Ribeiro et al., 2015).In most countries of the world, oral cancer occurs more in men than in women. Differences in gender is due to differences in indulgence in risk full behavior habits (tobacco and alcohol) by men and prolonged exposure to sunlight (lip cancer) (Warnakulasuriya, 2010).Lip cancer in white people is more than black people (Wurman et al., 1975). In white men of United States of America, lip cancer occurs more among all mouth cancers that its incidence is about 9/3\% in 100000 (Douglass and Gammon, 1984). The highest incidence of oral cavity cancer occurs in Melanesia, South and Central Asia and Central and Eastern Europe and the lowest in Africa, Central America and East Asia for both sexes. Oral cavity cancer mortality rate among men has dropped significantly in many countries including European and Asian countries over the past decade. But the continued rise has been seen in Hungary and Slovakia in several Eastern European countries. Increase in oral cavity cancer in women in European countries, mainly reflects the tobacco epidemic (Jemal et al., 2011).

Human Development Index is combination of three dimensions: a long and healthy life (based on life expectancy at birth), access to knowledge (based on a combination of the adult literacy rate) and a decent standard of life (based on gross national income) (Bray et al., 2013). Factors such as life expectancy, gross national income, literacy, health expenditures, physician density and efficiency of care systems play a constructive role in control of oral cancer mortality (Rao et al., 2013). As almost 47\% of cancer cases and $55 \%$ of cancer deaths occur in less developed areas of the world meaning countries with low or medium human development index (Soltani et al., 2015). 
In this study, a positive correlation was seen between life expectancy and standardized incidence rate which was not statistically significant. While, a negative correlation was seen between life expectancy and standardized mortality rate which was statistically significant. Increase in life expectancy helps increase in global cancer burden (Soerjomataram et al., 2012). Life expectancy of oral cancer varies considerably depending on the location of lesion, so that lip cancer rates are highest in middle ages among all sufferers (Welch and Nathanson, 1937) and it is also $63.38 \%$ for oral cavity cancer (Soerjomataram et al., 2012).

In this study, a positive correlation was seen between level of education and standardized incidence rate which was not significant. However, a negative correlation was observed between standardized incidence rate and standardized mortality rates which was statistically significant that could be due to the delay of referral and unthreatening in patients with low literacy levels. Studies from India, Pakistan and Turkey showed that a correlation exists between education and cancer. Those with lower education levels are at greater risk. A study in India found that even more illiteracy is more associated with oral cancer in comparison with lower literacy levels, (Rao et al., 2013). Another study showed that less education in population, increases death rates from cancer 2.6 folds compared to those who had higher education (Patel et al., 2012). Education Level may be related to behavior, health conditions or access to knowledge and resources that directly or indirectly affect the cancer and getting rid of it (Mahdavifar et al., 2015).

In this study, a positive correlation was seen between income level and the standardized incidence rate which was not statistically significant. While, a negative significant correlation was seen with the standardized mortality rate. Low socioeconomic status was significantly associated with increased risk of oral cancer in low and high-income countries across the universe (Allam and Windsor, 2014; Hobdell et al., 2003; Pawar et al., 2012). A meta-analysis of 41 case-control study around the world proved that, low socioeconomic status is an independent risk factor for oral cancer. People with manual jobs such as agriculture, trade and industry are at risk for oral cancer. In Sri Lanka, for example, tea garden workers are at greater risk (Rao et al., 2013). Another meta-analysis study showed that low socioeconomic and deprivation are significantly related to the risk of oral cancer compared to high-income socio-economic level people (Warnakulasuriya, 2010). One study showed that the elimination of socioeconomic inequalities in black Americans may omit deaths from early cancers occurrence as much as 2 folds which is a kind of racial inequality elimination (Patel et al., 2012). Low socioeconomic status may be related to low awareness about health, lack of access to health care, poor 
nutrition, poor work environment factors and poor living conditions associated with an increased risk of oral cancer (Warnakulasuriya, 2009b).Socio-economic status is associated with nearly all health outcomes in most countries. People with more education or income, have a long life and will experience less adverse events related to health (Crimmins and Saito, 2001).

\section{Conclusion}

Mortality rates and the incidence of oral cancer varies widely throughout the world as the highest amounts have been recorded in developing countries including India, Pakistan, Bangladesh, Hong Kong, Singapore and Philippines which oral cancer is recorded as the most common form of cancer in it. The prevalence of oral cancer is high in Asian countries, especially Southeast Asia. A positive and statistically non-significant correlation was observed between the lip and oral cavity cancer and human development index and its components including life expectancy at birth, average education level and income level per person. But also a negative significant correlation was observed with the standardized mortality rate and $\mathrm{HDI}$ and its components. This research is essential for better treatment in the world to reduce the incidence and mortality of cancer and to create a suitable platform for performing studies with the aim of determining the causes of increased incidence and mortality in the world. 


\section{References}

1. Ahluwalia, K.P., Yellowitz, J.A., Goodman, H.S., and Horowitz, A.M. (1998). An assessment of oral cancer prevention curricula in US medical schools. Journal of Cancer Education 13, 90-95.

2. Allam, E., and Windsor, J.L. (2014). Social and behavioral determinants of oral cancer. Dentistry 4, 1.

3. Ariyawardana, A., and Johnson, N.W. (2013). Trends of lip, oral cavity and oropharyngeal cancers in Australia 1982-2008: overall good news but with rising rates in the oropharynx. BMC cancer 13, 1.

4. Batista, A.C., Costa, N.L., Oton-Leite, A.F., Mendonça, E.F., Alencar, R.d.C.G., and Silva, T.A. (2010). Distinctive clinical and microscopic features of squamous cell carcinoma of oral cavity and lip. Oral Surgery, Oral Medicine, Oral Pathology, Oral Radiology, and Endodontology 109, e74-e79.

5. Bray, F., Jemal, A., Grey, N., Ferlay, J., and Forman, D. (2012). Global cancer transitions according to the Human Development Index (2008-2030): a populationbased study. The lancet oncology 13, 790-801.

6. Bray, F., Ren, J.S., Masuyer, E., and Ferlay, J. (2013). Global estimates of cancer prevalence for 27 sites in the adult population in 2008. International Journal of Cancer 132, 1133-1145.

7. Crimmins, E.M., and Saito, Y. (2001). Trends in healthy life expectancy in the United States, 1970-1990: gender, racial, and educational differences. Social science \& medicine 52, 1629-1641.

8. Dodd, R.H., Marlow, L.A., Forster, A.S., and Waller, J. (2016). Print and online newspaper coverage of the link between HPV and oral cancer in the UK: a mixedmethods study. BMJ open 6, e008740.

9. Douglass, C.W., and Gammon, M.D. (1984). Reassessing the epidemiology of lip cancer. Oral surgery, oral medicine, oral pathology 57, 631-642.

10. Elter, J.R., Patton, L.L., and Strauss, R.P. (2005). Incidence rates and trends for oral and pharyngeal cancer in North Carolina: 1990-1999. Oral oncology 41, 470-479.

11. Ferlay J, Soerjomataram I, Ervik M, Dikshit R, Eser S, Mathers C, Rebelo M, Parkin DM, Forman D, and Bray, F. (2016). GLOBOCAN 2012 v1.0, Cancer Incidence and Mortality Worldwide: IARC CancerBase No. 11 [Internet]. Lyon, France: International Agency for Research on Cancer; 2013. Available from: http://globocan.iarc.fr, accessed on 2/2/2016.

12. Ferlay, J., Soerjomataram, I., Dikshit, R., Eser, S., Mathers, C., Rebelo, M., Parkin, D.M., Forman, D., and Bray, F. (2015). Cancer incidence and mortality worldwide: sources, methods and major patterns in GLOBOCAN 2012. International journal of cancer Journal international du cancer 136, E359-386.

13. Ghoncheh, M., Mirzaei, M., and Salehiniya, H. (2016). Incidence and mortality of breast cancer and their relationship with the human development index (HDI) in the world in 2012. Asian Pacific Journal of Cancer Prevention 16, 8439-8443.

14. Hobdell, M., Oliveira, E., Bautista, R., Myburgh, N., Lalloo, R., Narendran, S., and Johnson, N.W. (2003). Oral diseases and socio-economic status (SES). British dental journal 194, 91-96. 
15. Jemal, A., Bray, F., Center, M.M., Ferlay, J., Ward, E., and Forman, D. (2011). Global cancer statistics. CA: a cancer journal for clinicians 61, 69-90.

16. La Vecchia, C., Tavani, A., Franceschi, S., Levi, F., Corrao, G., and Negri, E. (1997). Epidemiology and prevention of oral cancer. Oral oncology 33, 302-312.

17. Listl, S., Jansen, L., Stenzinger, A., Freier, K., Emrich, K., Holleczek, B., Katalinic, A., Gondos, A., Brenner, H., and Group, G.C.S.W. (2013). Survival of patients with oral cavity cancer in Germany. PLoS One 8, e53415.

18. Mahdavifar, N., Ghoncheh, M., Pakzad, R., Momenimovahed, Z., and Salehiniya, H. (2015). Epidemiology, Incidence and Mortality of Bladder Cancer and their Relationship with the Development Index in the World. Asian Pacific journal of cancer prevention: APJCP 17, 381-386.

19. Mahdavifar, N., Ghoncheh, M., Pakzad, R., Momenimovahed, Z., and Salehiniya, H. (2016). Epidemiology, incidence and mortality of bladder cancer and their relationship with the development index in the world. Asian Pacific Journal of Cancer Prevention 17, 381-386.

20. Malik, K. (2013). Human development report 2013. The rise of the south: Human progress in a diverse world. The Rise of the South: Human Progress in a Diverse World (March 15, 2013) UNDP-HDRO Human Development Reports.

21. Mukherjee, A., Biswas, J., and Roy, M. Viral origin of oral cancer: its remediation by phytochemicals.

22. Oliveira-Neto, H.H., Gleber-Netto, F.O., de Sousa, S.F., França, C.M., Aguiar, M.C.F., Silva, T.A., and Batista, A.C. (2012). A comparative study of microvessel density in squamous cell carcinoma of the oral cavity and lip. Oral surgery, oral medicine, oral pathology and oral radiology 113, 391-398.

23. Pakzad, R., Mohammadian-Hafshejani, A., Ghoncheh, M., Pakzad, I., and Salehiniya, H. (2015). The incidence and mortality of prostate cancer and its relationship with development in Asia. Prostate International 3, 135-140.

24. Patel, A.R., Prasad, S.M., Shih, Y.-C.T., and Eggener, S.E. (2012). The association of the human development index with global kidney cancer incidence and mortality. The Journal of urology 187, 1978-1983.

25. Pawar, H.J., Dhumale, G., and Singh, K. (2012). Relationship between sociodemographic factors, oral cancer in rural area of Maharashtra state, India: Case Control study. Indian J Basic Applied Med Res 1, 324-331.

26. Pereira, M.C., Oliveira, D.T., Landman, G., and Kowalski, L.P. (2007). Histologic subtypes of oral squamous cell carcinoma: prognostic relevance. Journal-Canadian Dental Association 73, 339.

27. Petersen, P.E. (2009). Oral cancer prevention and control-The approach of the World Health Organization. Oral oncology 45, 454-460.

28. Priya, M., and Lando, H.A. (2014). Tobacco control: an issue twinned with oral cancer control. International dental journal 64, 229-232.

29. Rafiemanesh, H., Mehtarpour, M., Khani, F., Hesami, S.M., Shamlou, R., Towhidi, F., Salehiniya, H., Makhsosi, B.R., and Moini, A. (2016). Epidemiology, incidence and mortality of lung cancer and their relationship with the development index in the world. Journal of thoracic disease 8, 1094-1102. 
30. Rao, S.K., Mejia, G., Roberts-Thomson, K., and Logan, R. (2013). Epidemiology of oral cancer in Asia in the past decade-an update (2000-2012). Asian Pac J Cancer Prev 14, 5567-5577.

31. Razi, S., Ghoncheh, M., Mohammadian-Hafshejani, A., Aziznejhad, H., Mohammadian, M., and Salehiniya, H. (2016). The incidence and mortality of ovarian cancer and their relationship with the Human Development Index in Asia. ecancermedicalscience 10.

32. Ribeiro, I.L.A., Medeiros, J.J.d., Rodrigues, L.V., Valença, A.M.G., Neto, L., and de Andrade, E. (2015). Factors associated with lip and oral cavity cancer. Revista Brasileira de Epidemiologia 18, 618-629.

33. Sankaranarayanan, R., Ramadas, K., Thara, S., Muwonge, R., Thomas, G., Anju, G., and Mathew, B. (2013). Long term effect of visual screening on oral cancer incidence and mortality in a randomized trial in Kerala, India. Oral oncology 49, 314-321.

34. Sciubba jj, R.j. (1999). Oral Pathology,Clinical Pathological.Correlation. 69-79.

35. Soerjomataram, I., Lortet-Tieulent, J., Parkin, D.M., Ferlay, J., Mathers, C., Forman, D., and Bray, F. (2012). Global burden of cancer in 2008: a systematic analysis of disability-adjusted life-years in 12 world regions. The Lancet 380, 1840-1850.

36. Soltani, S., Hafshejani, A.M., and Salehiniya, H. (2015). Trend of disability prevalence in Iran: An evidence to improve disability data. Journal of research in medical sciences : the official journal of Isfahan University of Medical Sciences 20, 531-532.

37. Stîngă, A., Mărgăritescu, O., Stîngă, A.S., Pirici, D., Ciurea, R., Bunget, A., and Cruce, M. (2011). VEGFR1 and VEGFR2 immunohistochemical expression in oral squamous cell carcinoma: a morphometric study. Rom J Morphol Embryol 52, 1269-1275.

38. Warnakulasuriya, S. (2009a). Global epidemiology of oral and oropharyngeal cancer. Oral oncology 45, 309-316.

39. Warnakulasuriya, S. (2009b). Significant oral cancer risk associated with low socioeconomic status. Evidence-based dentistry 10, 4-5.

40. Warnakulasuriya, S. (2010). Living with oral cancer: epidemiology with particular reference to prevalence and life-style changes that influence survival. Oral oncology 46, 407-410.

41. Welch, C.E., and Nathanson, I.T. (1937). Life Expectancy and Incidence of Malignant Disease: II. Carcinoma of the Lip, Oral Cavity, Larynx, and Antrum. The American Journal of Cancer 31, 238-252.

42. Wurman, L.H., Adams, G.L., and Meyerhoff, W.L. (1975). Carcinoma of the lip. The American Journal of Surgery 130, 470-474. 